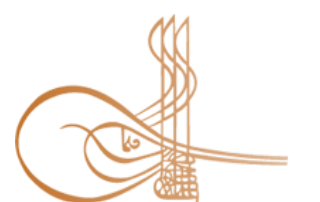

www.turkishstudies.net/social
Turkish Studies - Social Sciences

eISSN: $2667-5617$

Research Article / Araștırma Makalesi

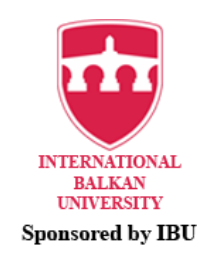

Sponsored by IBU

\title{
Asaf Hâlet Çelebi’nin Şiirlerinde Bilinçaltı Arayışları ve Mistisizm
}

\author{
Submarine Searches and Mysticism in Asaf Hâlet Çelebi's Poems
}

\author{
Eyüp Can Ekinci*
}

\begin{abstract}
Decomposition with the classical art tradition can be considered with the transformation of literature in the civilization circle. The modernization process that started with Tanzimat is the steps of breaking with the rhetorical tradition of Turkish poetry and connecting to a new cultural life with contemporary data. Western thoughts and concepts, which we see directly in the texts, determine the dominant literature in literature, and allow for secular discourse on the materialistic and positivist plane. However, the extroverted art anxiety of the republican intellectuals living in the Western-centered canon diverts some intellectuals of the period in the opposite direction. This separation is related to the effort to provide an introverted, mystical sense across an outwardly secular art base. Similarly, these poets, who have an intuitive understanding, approaching the outside world on the subconscious basis, constitute the important building block of abstract poetry. In this context, Asaf Hâlet Çelebi is another poet who distinguishes with the contemporary data of his period when it comes to the content of his works.
\end{abstract}

Structured Abstract: Decomposition with the classical art tradition can be considered with the transformation of literature in the civilization circle. The modernization process that started with Tanzimat is the steps of breaking with the rhetorical tradition of Turkish poetry and connecting to a new cultural life with contemporary data. Western thoughts and concepts, which we see directly in the texts, determine the dominant literature in literature, and allow for secular discourse on the materialistic and positivist plane. However, the extroverted art anxiety of the republican intellectuals living in the Western-centered canon diverts some intellectuals of the period in the opposite direction. This separation is related to the effort to provide an introverted, mystical sense across an outwardly secular art base. Similarly, these poets, who have an intuitive understanding, approaching the outside world on the subconscious basis, constitute the important building block of abstract poetry. In this context, Asaf Hâlet Çelebi is another poet who distinguishes with the contemporary data of his period when it comes to the content of his works. The tendency of the poet to establish this directional structure can be associated with the problems he faced at the point of context and reconciliation with his era. For instance, Asaf Hâlet Çelebi's being in contact with different times and phases from the point where he is located due to his subconscious, reverses the perception of geometric time at the point of modern thought. This first movement, which started with the negation of space and time, opens up space for the poet's self-directed time-making and ontological inquiries. This self-consciousness of the poet stands out from the materialistic poetry form, making the mystic movement points open. Another part of this separation, which became more evident in the second phase of the modernization phase, is in a dilemma that can be explained by the concept of "inner quest", which is indifferent to modern life dynamics. The fact that modern life and presentations cause a context problem in

* Doktora Öğrencisi, Niğde Ömer Halisdemir Üniversitesi, Sosyal Bilimler Enstitüsü, Türk Dili ve Edebiyatı Anabilim Dalı PhD Student, Niğde Ömer Halisdemir Üniversitesi, Graduate School of Social Sciences, Turkish Language and Literature ORCID 0000-0002-1746-4237

e.canekinci25@gmail.com

Cite as/ Atıf: Ekinci E.C. (2020). Asaf Hâlet Çelebi'nin şiirlerinde bilinçaltı arayışları ve mistisizm. Turkish Studies -

Social, 15(5), 2501-2509. https://dx.doi.org/10.47356/TurkishStudies.44518

Received/Geliş: 25 June/Haziran 2020

Accepted/Kabul: 20 August/Ağustos 2020

Copyright (C) INTAC LTD, Turkey
Checked by plagiarism software

Published/Yayın: 30 August/Ağustos 2020

CC BY-NC 4.0 
these intellectuals have left these poets indifferent to the data of modern life. This is seen in his poems as the negation of space, time and object. Poets who have a problem of context with the worldly data of modernism tend to seek an inner quest that opens up space for their existential inquiries. Asaf Halet Celebi, another poet of the republic that we have seen the most important effect of this search - with the modernity crisis. In the second half of the twentieth century, unlike the poets seeking outward innovation, Asaf Halet Çelebi's introversion is the starting point of his poetry in the poetic plane. Rhetorical decomposition with the contemporary poetry form is related to incompatibility with the thought form of its era and disconnection in context. The perception of a world with mental and substance pressure can be the mystical experience of breaking the resistance in the poet. This in particular puts a transcendental sense and an ontological attempt to attain absolute truth against the determinist worldview. Especially the images and word density used in his poems show what kind of search the poet is looking for. In this regard, while the poet accepts his childhood acts in the most natural way, he finds the folkloric acquisitions in the first stage of life and their accumulation under the subconscious. The most important issue that constitutes the poem form of Asaf Hâlet Çelebi is the effort to re-establish the time as a whole by skipping time intervals (in the past and present). This understanding, which is also based on the concept of spiritual life of Bergson's philosophy, is related to the time it takes on reality and inner life. Memories that fill the gap of the dynamic period in life are important factors that make up the outward experience of man. Filling the gaps behind the lived time with memories, the human creates a kind of memory inward curl, turning towards existence and expressing the mystical echoes in the subconscious. Therefore, the poet's contact with different points of the time points to the effort to create a perception related to the inner dynamics of the past. This leads to the dominant use of the concepts in his poetry in parallel with his past, that is, an inward orientation associated with his childhood, history and geography.

Keywords: Asaf Hâlet Çelebi, mystic, intuition, subconscious, time

Öz: Klasik sanat geleneğiyle ayrışma edebiyatın medeniyet dairesindeki dönüşümü ile birlikte düşünülebilir. Tanzimat ile başlayan modernleşme süreci, Türk şiirinin retorik geleneğinden kopuşun ve çağdaş verilerle yeni bir kültür hayatına bağlanışın adımlarıdır. Metinlerde doğrudan ifadesini gördüğümüz batılı düşünüş ve kavramların baskın şekilde edebiyatı belirlemesi, maddeci ve pozitivist düzlemde seküler söylem üretmeye imkân verir. Fakat Batı merkezli kanona bağlanış yaşayan cumhuriyet aydınlarının dışa dönük sanat kaygısı, dönemin bazı aydınlarını tersi bir istikamete yöneltir. Bu ayrışma dışa dönük seküler bir sanat kaidesinin karşısına içe dönük, mistik bir duyuş sağlama gayreti ile alakalıdır. Aynı şekilde sezgici bir kavrayışa sahip olan bu şairlerin de bilinçaltı münasebetiyle dış dünyaya yaklaşması soyut şiirin önemli yapı taşını oluşturur. Bu bağlamda eserlerinin içeriği söz konusu olduğunda döneminin çağdaş verileriyle ayrışan bir diğer şairi Asaf Hâlet Çelebi' dir. Şairin bu yönlü bir yapı kurma eğilimi, dönemiyle bağlam ve uzlaşım noktasında yaşadığı sorunlarla ilişkilendirilebilir. Sözgelimi Asaf Hâlet Çelebi’nin bilinçaltı münasebetiyle bulunduğu noktadan farklı zaman ve evrelerle temas içinde bulunması, modern düşünce noktasında geometrik zaman algısını tersyüz eder. Uzam ve zamanın yadsınması ile başlayan bu ilk hareket, poetik açıdan şairin kendine dönük bir zaman kurma ve ontolojik sorgulamalarına alan açmaktadır. Şairin bu kendine dönük bilinci maddeci şiir formundan sıyrılarak mistik hareket noktalarını da açık hale getirmektedir.

Anahtar Kelimeler: Asaf Hâlet Çelebi, mistik, sezgi, bilinçaltı, zaman

\section{Giriş}

Türk kültür hayatının modernleşme safhasında, modern düşüncenin sistematik değerleriyle etkileşimin dinamik surette olduğu aydınlarımızca yadsınamaz durumdur. Özellikle Batılı tesir altında kalan toplum hayatımız, buna edebiyat sahasını da dâhil etmesi ile metinlerin söylem üretme biçiminde, eskiyle arasında belirgin bir ayrışma teşekkül ettirdiği yine metin merkezli incelemelerle sabittir. Özellikle Tanzimat ile başlayıp cumhuriyet ile daha sistematik ve belirgin hale gelen bu değişim alanına birçok aydın sürüklendiği gibi, bu yönelime karşı direnç gösteren gelenekçi şair ve yazar topluluğu daha tedbirlidir. Modernleşme evresinin ikinci aşamasında, daha da belirgin hale gelen bu ayrışmanın bir diğer kesimi olan, modern yaşam dinamiklerine kayıtsız durumdaki aydın gurubu "içsel arayış" kavramıyla açıklanabilecek ikilem hali içerisindedir. Modern yaşam ve sunuların bu aydınlarda bir bağlam problemi doğurması, şairleri modern yaşamın verilerine karşı 
kayıtsız bırakmıştır. Bu ise şiirlerinde uzamın, zamanın ve nesnesinin yadsınması şeklinde görülür. Modernizmin dünyevî verileriyle bağlam problemi yaşayan şairler varoluşsal sorgulamalarına alan açan içsel bir arayışa yönelirler. $\mathrm{Bu}$ arayışın en önemli etkisini -modernite kriziyle birliktegördüğümüz cumhuriyetin bir diğer şairi Asaf Hâlet Çelebi'dir.

Yirminci yüzyılın ikinci yarısında, dışa dönük yenilik arayışındaki (Kemal, 1985: 14) şairlerin aksine Asaf Hâlet Çelebi'nin içe dönük bu arayışı, poetik düzleminde şiirlerinin de kalkış noktasını oluşturur. Çağdaş şiir formuyla retorik olarak ayrışma, devrinin düşünce formuyla uyuşmazlık ve bağlam noktasında kopukluk ile alakalıdır (Şamlığlu, 2020: 104). Çağın akıl ve madde tazyikli bir dünya algısı, șairde bu direnci kırmaya yönelik mistik deneyim halini alır. Bu özellikle determinist dünya görüșünün karșısına aşkın (transandantal) bir duyuş ve ontolojik olarak mutlak hakikate ulaşma çabasını koyar. Necip Fazıl ve Sezai Karakoç'un Batı şiirinin bütün imkânlarını kullanarak kendi öz medeniyet ve düşünce perspektifi ufkunda ürettiği şiirler (Polat, 2017: 430) yine bu ruha bağlı olarak yeni bir şiir damarı oluşturma noktasında Asaf Hâlet poetikasını da geçerli kılar. Özellikle şiirlerinde kullandığı imgeler ve kelime yoğunluğu şairin ne türden bir arayış içerisinde olduğunu gösterir. Çünkü şair modern dünyanın gündelik verilerine kayıtsız kalırken aynı zamanda varoluşunu irdelemek suretiyle "şuuraltı" ile etkileşim halindedir: "Şair her şeyden önce şuur altı ile çok temas etmesi icap eden bir insandır. Ancak şuur altındaki birikintileri, şuurun müdahalesiyle meydana çıkartır ki bu, sanatkâr olan şairin kudreti nisbetinde muayyen bir ruh hâletini ortaya koymayı istihdaf eden bir fiildir. Bunu şair yahut sanatkâr kendi filtresinden, süzgecinden geçirmiştir." (Baydar, 1960: 67). Dolayısıyla şiirlerinin oluşum noktası sezgisel kavrayış olarak yorumlandığında, Asaf Hâlet Çelebi için daha derinlikli ve çeşitli yönelimlerde bulunan şair yorumu yapmak mümkündür. Özellikle şairin varlık arayışında nouméne varlık alanını tanıma gayreti içerisinde olması, "şuuraltı" fikrini gündeme getiren en önemli hususlardır. Bu bakımdan şairin poetikasını da yönlendiren temel güç, modern verilerinden soyutlanarak iç arayışında benliğini kavrama çabası olarak görülebilir.

Şairin bu bağlamda ilk arayış noktası çocukluğudur. Özellikle soyut şiir fikrine yöneldiği zaman, dış etkenlerin kavramsal algılayışından sıyrılarak imgelere dönüşmenin ilk evresi şair adına çocukluğudur: "Şekilden ziyade meâle ehemmiyet veren, şuurdan ziyade tahteşşuurî denilen, müşahhas edebiyattan ziyade mücerret edebiyatı terviç eden zümreye hitap ediyorum. Hazineler bizim tahteşşur varlığımızdır. Eskiyi okumak veya okumamak bizi tesiri altında bulundurmamal, kör taklidcilikten vaz geçmeliyiz. Çocukluğumuza dönmesek bile çocukluğumuzdaki saf ve samimi varlı̆̆ımıza dönmeliyiz." (Çelebi, 1938: 4). Bu bakımdan şair çocukluk edimlerini en doğal haliyle kabul ederken, yaşamın ilk evresindeki folklorik kazanımları ve bunların şuuraltında birikimini önemli bulur. Asaf Hâlet Çelebi'nin şiir formunu oluşturan en önemli husus, zaman aralıkları atlayarak (geçmiş ve bugün içleminde) zamanı bir bütün olarak yeniden kurma çabasıdır. Bergson felsefesinin ruhî hayat kavramına da dayanan bu anlayış, realiteye dayandırdığı süre ve içsel hayat ile ilgilidir:

\begin{abstract}
"Bizim etrafimızda ve bizde hakikî realite akıcllık (mobilité)dır. Ruhî hayat, yayıllı̧sı esnasında her an yeni vasıflar (qualité) kazanan, sürekli yenilikler fişkırması olan ekleme suretiyle tevali (succession par juxtaposition)nin tam zıttı organlaş̧mış, birbiri içerisinde erime olayln ihtiva ede, orijinaliteye sahip bir realitedir. Ruhta bütün unsurlar birbirine karışırlar. Namütenahi titreşimler halinde birbirlerinin içerisinde erirler. Mazi ile hal daima beraber bulunur; her ikisi de ilerleyerek kabarır ve istikbali hazırlar." (Topçu, 2011: 47).
\end{abstract}

Bu görüş ekseninde Kant ve Descartes felsefesinin geometrik zaman algısının aksine geçmiş ile şimdi arasında girift bir kavrayış olarak düşündürür. Modern felsefenin tek taraflı bir zaman algısını reddetme ve zamanı varlık içerisinde sonsuz bir hareket olarak kavrama söz konusudur. Şairin içsel yolculuğunda zamanı sezgisel bir duyuşla kavraması, hayatın farklı dönem ve anlarına yönelerek şiir 
kurmasının önünü açar. Çocukluk etkileri bu arayışın ilk adımı olarak ele alındığında Ömer Çocuk şiiri düşünceyi destekleyen ipuçları içermektedir:

“ömer çocuk odamda yok
bu damda yok
kucağımda
koynumda yok

bu içimin içinde var" (Çelebi, 2016: 76)

Şairin "ömer çocuk" ibaresini "yok"luk ile tamamlaması, dışsal olgularla tanımlanabilir "oda", "dam", "kucak" ve "koyun" gibi somut ibarelerle arayışın sonuçsuz kaldığını göstermektedir. Oysa aynı arayışın "içimin içinde" açar ibaresi ile ulaştığı nokta "var" açar ibaresi ile birleştiğinde, nesneler dünyasının ötesinde, şuurun derinliklerinde bir arayış ihtimali daha geçerlidir. Bu bağlamda şairin şiirinde ilk hareket noktasını oluşturan çocukluk edimleri denilebilir ki "tahteşşuur" olarak nitelendirdiği derinliklere yönelip sezgisel duyuş noktasını oradan başlatmasıdır. Yine Mağara şiirinde;

\section{“içimdeki mă̆arada}

kurumuş ölüler yatar

(...)

içimdeki mă̆arada

bir yı̆̆ın kitap var" (Çelebi, 2016: 15)

kullanılan "iç" ve "mağara" ibareleri, aynı imaj ve kullanımın devam ettirdiğini gösterir. Sözgelimi Saf Şiir başlıklı makalesinde, Hz. Peygamber' in "Muhakkak ki Allah'ın, arşın altında anahtarları şairlerin dilleri olan bir takım hazineleri vardır." hadisine dayanarak yaptığı yorumda, varlığın özündeki mücerret manayı kavrama noktasında mistisizme dayalı bir söylemin önünü açar ki bu durum varoluşsal kodlara yeniden bağlanma hali olarak yorumlanabilir. Bilal Kırımlı'nın da ifade ettiği ş̧ekliyle Çelebi'nin şiirlerinde belirleyici etken "çocukluk intibaları ve masalların birikintilerinin bulunduğu şuuraltı etkisiyle, Budizm ve tasavvufun tesirinde kozmolojik ve paleontolojik malumata dayalı sezişlerdir." (Kırıml1, 1995: 181) modern verilere karşı kayıtsızlık, uzam ve zaman denkleminin kurulmasını engellemekte ve zamanın tersyüz olmasına imkân tanımaktadır. Asr-1 Saadet'e dönüşü simgeleyen Sen şiiri varoluşsal irdeleme, içsel duyuş ve modern zaman algısının tersyüz edilme biçimine örnek teşkil etmektedir:

"Zamanlar içinden göçtüm

Duvarın taşın içinden geçdim

Dă̆ı taşı bırakdım

sana geldim" (Çelebi, 2016: 107)

Zamandaki döngüselliğe imkân veren temel etken, Çelebi şiirinin de belirleyici faktörüdür. Çünkü şairde çağını yadsırken, içe dönük bir arayış halinde olması zamanı bir bütün olarak kavramasını mümkün kılar. Mehmet Kaplan'ın belirttiği gibi şair bütün zaman ve mekânları adeta beraber yaşamaktadır: "Bütün zamanları bütün mekânları birden yaşamak, kelimenin tam anlamıyla beşerî ve daha fazlast, tabir caizse, 'kainatî' olmak, çeşitli medeniyetlerin insanlartyla hayvanlar ve nebatlarla birleşmek, bir nevi varlık mistisizmi: Asaf Hâlet Çelebi'nin şiirlerinde hâkim olan düşünce budur." (Kaplan, 2014: 169). İnsanın bugünkü tecrübe ve düşünce dünyasına etki eden mazinin hatıraları ise, insan mazi ve hâli birlikte yaşıyor denebilir. Bu bağlamda, matematik zamanın doğrusal bir hat üzerinde sıralı hareketi yorumunun aksine, zamanı daima içe doğru kıvrımlı ve geriye 
salınımlı olduğu görüşünde olan ve geometrik zaman algısını tersyüz eden bu düşünüş, Belgson sezgi felsefesinin de temel konularından birini oluşturmaktadır:
"Demek ki vücudun rolü dışarlya tepkiler yapmak üzere varlıklardan uyaranlar almaktadır. Bu tepki ne için gelişigüzel olmuyor? Çünkü bu tepki, seçimi mazinin tecrübeleri arasindan yapıyor ve birbirine benzeyen hallerin daima kendi arkalarına ylğglkları hatıraları davet ediyor. Bu sebepten denilebilir ki maziye bağlı bir manzara içi (perspective)ne sahip olmadan istikbale uzanamiyoruz. Faaliyetimizin bizi mütemadiyen ileriye doğru itmesi kendi arkasında boşluk bırakıyor; bu boşluğa hatıralar hücum ediyor ve böylelikle hafiza, bilgi sahasında bir nev'i kendi üzerine kirlma (répercussion) olayın meydana getiriyor." (Topçu, 2011: 93).

Hayattaki dinamik sürenin boşluğunu dolduran hatıralar, insanın dışa dönük tecrübesini oluşturan önemli etkenlerdir. Yaşanmış sürenin ardındaki boşlukları hatıralar suretiyle dolduran insan, bir nevi hafızada içe doğru kıvrılma yaratmakta, varoluşa yönelerek şuuraltındaki mistik yankıları dışa vurmaktadır. Dolayısıyla şairin zamanın farklı noktalarıyla temas etmesi, geçmişin içsel dinamikleriyle bağlantılı bir algı yaratma çabasına işaret etmektedir. Bu da şiirlerindeki kavramların geçmişiyle paralel baskın kullanılması, yani çocukluğu, tarihi ve coğrafyasıyla bağlantılı bir içe yönelme hâlini doğurmaktadır. Bu duyuş özellikle kendi şiiri üzerinde (kurucu özne olarak) şairin zamanı yeniden kurma deneyimidir. Yine Mısrı Kadîm şiirinde;

"zaman unutulunca mısrı kadîm yaşanabiliyor

kendimi unutunca seni yaşıyorum" (Çelebi, 2016: 18)

şeklinde geçen ibareler dikkate alındığında şairin belleğindeki "zaman"1, "unutmak" kavramıyla dışlaması, yaşanılan geometrik zaman algısının şair tarafından ötelenmesi olarak yorumlanmalıdır. Çünkü zamandan kendisini soyutlaması ile Mısrı Kadim'i yaşaması ve kendini orada bulması, köklere yönelip oradaki arayışını sürdürme şeklidir. Çelebi'nin Sanatta Eskimeyen Şey başlıklı yazısında yine poetikasını belirleyen ifadeleri görmek mümkündür: "Malzemenin sağlamlı̆̆ kurulduğu zamanlardaki bütünlüğ̈̈ mimarisinin dayanıklılığını temin eder." (Çelebi, 1954: 22-23). Dolayısıyla şair çağın sunularını dışta bırakarak varoluşa dair sağlam bir dayanak bulma amacındadır. Şiirinde kullandığ1 "zamanın içinden göçtüm" mısraı dikkate alındığında yine sezgisel bir duyuşa bağlı olarak "zaman" ve "iç" ibarelerinin birlikte kullanımı şuuraltı yönelimlerini daha görünür kılar. Bu bağlamda Çelebi, modernitenin sacayağını oluşturan zaman, uzam ve nesne denklemini kuramaması şairi şuuraltına ve oradaki "hazineleri" şiir dilinde ifadeye yöneltmektedir. Bu noktada şairin "iç", "ayna", "zaman", "rüya", ve "masal" kelimelerini yoğun olarak tercihi tesadüfî̀ değildir.

Soyut şiirin hatlarını oluşturan sezgisel duyuş, Paul Valéry'nin şiirle ilgili görüşünde belirttiği gibi içsel sorunların ifadesi şeklindedir. Bergson felsefesinin temelini alan bu görüş "estetik sezgi" kavramıyla ifade edilen, dış âleme kalp ile yönelen ve onu içsel duyuş formuyla kavrayıp tekrar şekil veren sanatkâr yaklaşımı ile ilgilidir. Çünkü madde ile ruh arasındaki perdeyi kaldıran yine şairin estetik duyuşudur. Bu yönelim ise insana has bir sezginin maddeye şekil vermesi ve onu zekâ ile birlikte eritmesidir: "Bir tür iç sorunların ve çözümlerin hareketi ve çoğulluğu. Bir başka yandan, bu şiir denen mesele ilginç bir yapıya sahip olmasl, yaratma ihtiyacı haricinde hiçbir ihtiyacı karşılamamasl, olmayan veya derinden gizlice hissedilen şeylerden bahsetmesi hasebiyle olağan konuşmadan epey bir farklıdır: Bu öyle tuhaf bir mesele ki sanki konuşandan başka birisi tarafindan yazılmış ve dinleyenden başka birisine hitap ediyormuş gibidir. Kısacası, 'dil içinde dildir." (Valéry, 2020: 78). Dolayısıyla Valéry'nin soyut şiiri tanımlarken yaptığı tarifi, Asaf Hâlet Çelebi’nin bu arayışını destekler niteliktedir. Şiir hakkındaki görüşlerini içerdiği bir dizi yazıda 
müşahhas malzemelerle mücerret bir âlem yaratmak (Çelebi, 1954: 15-16) fikrinde sabit olması fakat bu semiyotik birliği zaman ve mekânın çok üstünden kurması ayrıca düşünülmesi gereken şeylerdir. Çünkü Hilmi Yavuz'un da belirttiği gibi Asaf Hâlet Çelebi'nin çoğu şiirinde mistisizm büyük rol almakta ve bu düzeyde imgeler yaratan şair için zaman ve mekân bahis mevzuu olmamaktadır (Yavuz, 2013: 277). Şairin bu temayülü günümüz modern insanına çok farklı zaman aralıklarından seslenme imkânı sağlamaktadır. Kunâla şiirinde ise yaratılıştan başlayarak insanlığın değişimi ve kâinatın sırlarını anlamaya çalışan, seyir halinde bir şair karşımıza çıkmaktadır:

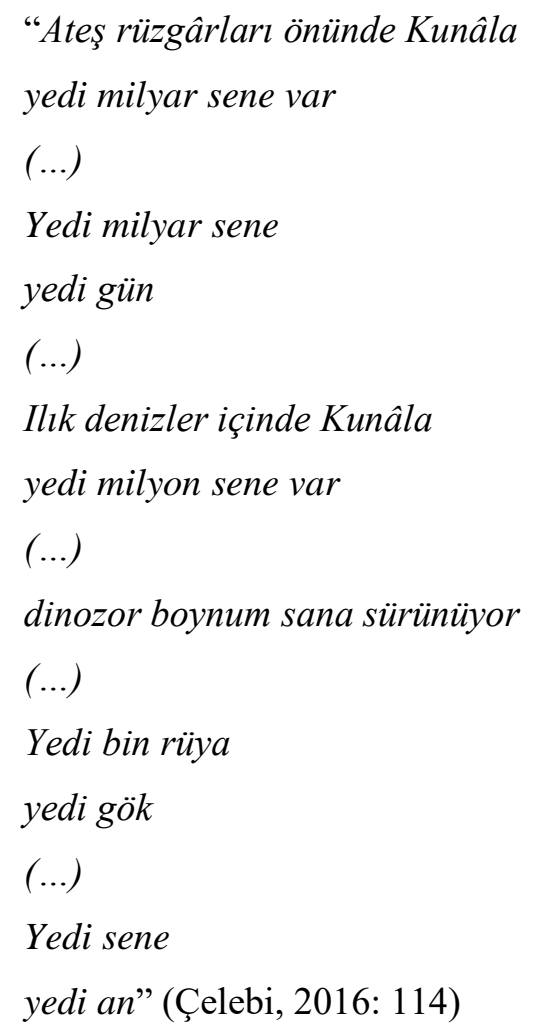

Tasavvuf ve mitsel dünyanın arkaik metinlerinde bulunan "yedi" ibaresi, "ateş", "rüzgar" ve "deniz" kavramları ile kainatın sırlarına vakıf olma ve zamansal süreçte geçirdiği değişim vurgulanmaktadır. Evrenin yaratılışına bağlı olarak şair bu durumu yine tasavvuf penceresinden vermeye çalışır. Çünkü "yedi gün" ve "yedi gök" ibareleri arkaik metinlerde ve üst anlatılarında tasavvufî söylem düzeyinde ifadelerdir. Bu durum varoluşsal kavrayışın sezgisel imgeleri olarak düşünüldüğünde, şairin çağdaş zaman algısını aşıp şuuraltı temasına bağlı olarak arkeolojik bilgiye ulaşma amacı taşıdığı söylenebilir.

Tüm bu söylem analizleri içerisinde Asaf Hâlet Çelebi'nin arayışını sürdürdüğü bir diğer alan, Doğu ve Budizm temelli alt yapısı güçlü olan felsefelerdir. Bu durum aslında insanlığın mitsel ve arkaik dönemde ortak imge ve sembollerini içeren hafiza ile ilgilidir. Nitekim Hilmi Yavuz, Asaf Hâlet Çelebi'nin şiir dilindeki simgesel ağı şöyle yorumlar:

'Batı düşüncesinin 'hayatta en hakiki mürşit ilimdir', özdeyişinde ifadesini bulan pozitivist ve entelektüel zihniyetinin, Türk insanına yegâne alternatif olarak dayatıldığı bir dönemde, Tanpınar'in deyişi ile 'iç insan'a yönelmek. Akll kadar, insanı onun duygularının yaptığını bilmek. Akıl kadar arketipsel duyarlılıkları (hatta irrasyonaliteyi!) öne çıkarmak. İnsanın sadece akıldan ibaret olmadiğını dile getirmek. Bunun için Doğu'ya, tasavvufa, Budizm'e dönecekti yüzünü... Kolektif hafizadaki arketipleri gömüldükleri zihinden aylklamak... Ve bu 
arketipleri, bir duyarlık için şiirsel işaret (poetical sing) olarak kullanmak! Işaret, Doğu'dan geldi!'” (Kırıml1, 1995: 96-97). ${ }^{1}$

Bu bağlamda modern düşünce ve onun önermelerini sorunsallaştıran şairin, şuuraltı teması ile içsel deneyim kurduğu alan tasavvufun yanı sıra Doğu mistisizmi ve Buda felsefesidir. Çünkü Yavuz'un "arketipleri bir duyarlık için şiirsel işaret... olarak kullanmak!" görüşü, Foucault'daki "söylemsel birliğin" varlık alanına çekilmek şeklinde de yorumlanabilir. Tam da bu noktada Çelebi’nin zamansal bütünlük olarak vermeye çalıştığ 1 şeyin, zihnin arketipinde kolektif hafiza ile alakalı olan sürecin şiir dilinde simgesel olarak aktarımı şeklindedir. Sözgelimi Sidharta şiirinde, evrenin varoluşsal zeminini arkaik metinlerin söylemsel birliği içerisinde açıklandığını görmek mümkündür:

$$
\begin{aligned}
& \text { "niyagôdhâ } \\
& \text { koskoca bir ağaç görüyorum } \\
& \qquad \text { ufacık bir tohumda } \\
& \text { o ne ă̆aç ne tohum } \\
& \text { am mani padme hum (üç kere)" (Çelebi, 2016: 58) }
\end{aligned}
$$

Asaf Hâlet Çelebi'nin beslendiği kaynağın mistisizm ve tasavvufun çekim gücüne bağl1 olması, onu insanlığın ontolojik sorgulamalara götürmektedir. Sözgelimi "om mani padme hum" ibaresini kullanarak Budizm'in esrime ifadelerine atıf yapması bu sorgulamanın daha çoğulcu bir zeminde yaptığını kanıtlar niteliktedir. Yine bir arayış paralelinde şairin imlediği "koskoca bir ă̆aç görüyorum/ufacık bir tohumda" mısra1 varoluşsal özü kavrama çabasına dönük mistik ifadelerdir. Asaf Hâlet Çelebi'nin bu etkiyle kurduğu şiirsel dile, Yunus Emre'nin 13. yüzyılda yazmış olduğu;

"Yine sordum çiçeğe boynun neden ĕgridir

Çiçek eydür ey derviş kalbim Hakka doğrudur." (Kaplan, 1955: 56)

mısraları karşılık gelebilir. Çünkü mısralardaki imgesel bütünlük, felsefî anlamda kâinatın merkez sorusu, tasavvufun tevhid fikri ile açıklamaya eğilimlidir. Aynı şekilde Spinoza felsefesinin de açıklamaya çalıştığı Tanrı'yı, kâinatı ve tüm mahlûkatı bir tek kavramla (cevher, öz) (Goethe, 2009: 58) ifade etme düşünsel yorumuyla doludur. Panteizmin kâinatı ve yaratılış formu ile bağlantılı olan her şeyi varlık/yokluk düalizmi ile açıklama çabası, tasavvufî düşüncenin kendini var(madde) olanda yok(ruh) olma fikrini içerir.

Bu bağlamda Asaf Hâlet Çelebi'nin de şiirlerinde "vahdet-i vücud” felsefesini yoğun işleyen bir şair olması, şiirini ifade ediş biçimini Yunus Emre, Cüneyd-i Bağdadî ve Hallac-1 Mansur gibi tasavvuf düşünürlerinin fikirleri ile birlikte düşünmeyi gerektirir. Varlığın mistik yönelimi sezgisel bir duyuş ve mutlak olanı kavrayış şeklinde harekettir. Bu yönelim insanın dinamik din tasavvuru alanında mutlak iyiye ulaşmak için eşyanın özünde derinleşmesi ve madde düzeyindeki varlığını mutlak olanda eritmesi olarak düşünülebilir: "Gövdesel varlıktan kurtularak tanrısal varllğa katılma; İslâm gizemcilerinin (mutasavvif) gerçek amacını böyle özetlemek olanaklı. Bu bağlamda İslâm gizemciliği (tasavvuf) bir yokoluşu, yokluğu değil; sonunda yine bir tür var oluşu, sonsuza dek varoluşu düşünür. Bir yokolma (fena) söz konusudur; ama bu tanrıda yok olmadır (fenafillah). Gövdebirliği, varlıkbirliğidir (vahdet-i vücud) ön görülen." (Dara, 1985: 30). Dolayısıyla şairin mistik hareket noktasına imkân veren hususlar kendine dönük bir zaman bilinci ve şuuraltı eğilimlerle ontolojik sorgulamalarına alan açmasıdır. Bu durum insanın eşyayı salt madde düzeyinde

\footnotetext{
${ }^{1}$ Hilmi Yavuz'un 1 Mart 1993 tarihli mektubu (aktaran) Bilal Kırımlı, Asaf Hâlet Çelebi Hayatı, Eserleri, Sanatı ve Fikirleri, Doktora Tezi, Atatürk Üniversitesi Sosyal Bilimler Enstitüsü, Erz., 1995, s. 96-97.

${ }^{2}$ Edebi eserlerin özellikle arkaik analizi yapıldığında, Foucault, düşünceyi harekete geçiren apriorilerin anlatıcıda mevcut surette bulunduğu ve bu önsel hareketin metni yeniden kurmaya olanak verip özerklik kazandırdığı görüşündedir. Bk. Michel Foucault, Foucault ve Bilginin Arkeolojisi, (Çev. Veli Urhan), Birey Yay., İst., 2002.
} 
algılamasının ötesine geçerek, maddenin kabuğunu kırıp onun özündeki aslî unsuru kavrama ve kendini onunla bütünleştirme çabasıdır. Sanatkârın estetik duyuşundaki dış âlemin perdesini aralaması da işte bu kendine dönük bilinç oluşturması ile ilgilidir.

\section{Sonuç}

Modern dünya verileriyle ayrışma yaşayan ve içe dönük kendilik bilincine sahip olan şairlerden biri de Asaf Hâlet Çelebi'dir. Şiirlerinde baskın olarak kullandığı kavramlar madde âleminin ötesinde, soyut şiirin bilinçaltı hareketleriyle kurduğu sanat yapısının izlerini taşımaktadır. $\mathrm{Bu}$ durum saf süreyi yaşayan insanın daima içe kıvrımlı zamanını dış âleme yansıtarak, madde düzeyinde kavradığı eşyayı kendi şuurunda eritmesi anlamına gelmektedir. Bu durum zekânın eşyaya olduğu gibi yaklaşması değil de bireyin kendi zamanına dönük bir eşyayı yorumlama halidir. Estetik sezgi kavramıyla Bergson'un da açıklamış olduğu ya da Asaf Hâlet Çelebi'nin kendi poetikasını müşahhas malzemede mücerret manayı keşfetmek olarak gördüğü durum, tam olarak nesneye saf algı ve sezgiyle yaklaşan sanatkârın olayları kavrayışına denk düşmektedir.

Şiirin kendine dönük bu zaman algısı, döneminden sıyrılarak farklı zaman ve medeniyetlerle tarih bilinci noktasında temas halinde bulunmasına olanak tanır. Varlık alanıyla kurulan bu bağ şairin aynı zamanda modern dünyadaki içsel arayışına olanak vermektedir. Çünkü başta da belirttiğimiz gibi çağdaş verilerle uyuşmazlık noktasında bağlam problemi yaşayan Çelebi, kendilik bilinci kurduğu şiirlerinde ontolojik sorgulamalarını farklı zamanlara yönelerek yapmaktadır. Bu yönelimin ilki şairin benliğini vücuda getiren çocukluk güdüleridir. Şairin bilinçaltına bağlı olarak içsel arayışındaki ilk etkileşim noktası ise çocukluğunun en saf duygularıdır. Kendine dönük zaman bilincinin bir diğer yönelim noktası ise şaire varlığıyla ontolojik sorgulamada buluștuğu kültür ve geleneğidir. Özellikle Mısrı Kadim ve Mağara şiirlerinde içsel yönelim hali kültürel formda bir bağlam aramasıyla ilgilidir. Çünkü modernitenin zaman ve uzam verilerini yadsırken aynı şekilde içe dönük zaman bilinci şaire varlık değerini hatırlatmaktadır. İşte bu varlık sorgulaması dikkatle incelendiğinde şairin içsel arayışında varlık alanlarıyla kurduğu temaslar daha açık hale gelecektir.

\section{Kaynakça}

Baydar, M. (1960). Edebiyatçılarımız Ne Diyorlar?. Ahmet Halit Yaşaroğlu Kitap.

Çelebi, A.H. (2016). Bütün Şiirleri. (Haz.) Selahattin Özpalabıyıklar. Everest Yayınları.

Çelebi, A.H. (1954). Sanatta Eskimeyen Şey. Ístanbul Dergisi, 8(6), 22-23.

Çelebi, A.H. (1938). Türk Ruhunda Mücerret. Ses, 4(12), 5.

Çelebi, A.H. (1954). "Mücerret Şiir”, Benim Gözümde Şiir Davası. İstanbul Dergisi, 12(10), 19-20.

Dara, R. (1985). İç Slzıları. Dayanışma Yayınları.

Foucault, M. (2002. Foucault ve Bilginin Arkeolojisi. (Çev.) Veli Urhan. Birey Yayıncılık.

Goethe, J.W. (2009). Doğu Batı Divanı, (Çev.) Senail Özkan. Ötüken Yayınları.

Kaplan, M. (1955). Yunus Emre ve Nebatlar, C. 12, Türkiyat Mecmuast.

Kaplan, M. (2014). Edebiyatımızın İ̧̧inden. Dergâh Yayınları.

Kemal, M. (1985). Acılı Kuşak. De Yayınları.

Kırımlı, B. (1995). .Asaf Hâlet Çelebi Hayatı, Eserleri, Sanatı ve Fikirleri [Doktora Tezi]. Atatürk Üniversitesi Sosyal Bilimler Enstitüsü.

Polat, A. (2017). Necip Fazıl Şiirinde Batılılaşmanın Getirdiği Kökensel Korku ve 'Özne' Direnişi, Turkish Studies, 12(29), 427-434. 
Sazyek, H. (2004). Asaf Hâlet Çelebi Bütün Yazıları, Yapı Kredi Yayınları.

Şamlığlu, K. (2020). Felsefî Bir Sıtmanın Güdümünde Âsaf Hâlet Çelebi, Gazi Türkiyat, 26/Bahar, 99-104.

Topçu, N. (2011). Bergson, Dergâh Yayınları.

Valéry, P. (2020). Şiir Sanatı, (Çev.) Ahmet Ölmez. KTB Yayınları.

Yavuz, H.(2013). Edebiyat ve Sanat Üzerine Yazılar, Yapı Kredi Yayınları. 